\title{
Ascending aortic dilatation is rarely associated with coronary artery disease regardless of aortic valve morphology
}

\author{
Veronica Jackson, MD, PhD, ${ }^{a}$ Maria J. Eriksson, $\mathrm{MD}, \mathrm{PhD},{ }^{\mathrm{b}}$ Kenneth Caidahl, $\mathrm{MD}, \mathrm{PhD},{ }^{\mathrm{b}}$ \\ Per Eriksson, $\mathrm{PhD},{ }^{\mathrm{c}}$ and Anders Franco-Cereceda, $\mathrm{MD}, \mathrm{PhD}^{\mathrm{a}}$
}

\begin{abstract}
Objective: Differences in clinical presentation between patients with tricuspid aortic valves (TAVs) or bicuspid aortic valves (BAVs) and aortic valve disease are evident. Whether these differences can be attributed to differences in cardiovascular risks remains uncertain.
\end{abstract}

\begin{abstract}
Methods: Patient characteristics, echocardiographic findings, medical history, medication, and laboratory findings were evaluated in 702 patients with aortic valve and/or ascending aortic pathology; 202 also had concomitant coronary artery disease.
\end{abstract}

Results: A BAV was commonly found in patients with isolated valve disease (BAV 47\%, TAV 53\%) and frequently associated with ascending aortic dilatation (BAV 80\%, TAV 20\%). In patients with coronary artery disease, a TAV was commonly found (TAV 84\%, BAV 16\%). The combination of ascending aortic dilatation and coronary artery disease was markedly rare regardless of valve morphology (TAV, 7 out of 38; BAV, 6 out of 127). The distribution of valve pathology and clinical parameters was similar in patients with TAV and BAV with coronary artery disease $(P \geq .12)$. Without coronary artery disease, parameters associated with cardiovascular risks were more often seen in patients with TAV than in patients with BAV $(P \leq .0001)$.

Conclusions: Coronary artery disease is uncommon in surgical patients with BAV, but it is associated with TAV, advanced age, and male gender. Coronary artery disease and ascending aortic dilatation rarely coexist, regardless of valve phenotype. Differences in the prevalence of coronary artery disease or ascending aortic dilatation between patients with TAV and BAV are not explained by differences in cardiovascular risks or the distribution of valve pathology. (J Thorac Cardiovasc Surg 2014;148:2973-80)

Supplemental material is available online.

A bicuspid aortic valve (BAV) is the most common cardiac malformation, with an estimated prevalence of $0.5 \%$ to $2 \%{ }^{1}$ and a male to female ratio of $3: 1 .^{2}$ It is believed to be autosomal dominantly inherited with reduced penetrance ${ }^{3}$ and is associated with other congenital cardiovascular lesions. ${ }^{4}$

Typically a BAV fails earlier in life and BAV patients are approximately 10 years younger than patients with tricuspid

\footnotetext{
From the Cardiothoracic Surgery Unit ${ }^{\mathrm{a}}$ and Clinical Physiology Unit, ${ }^{\mathrm{b}}$ Department of Molecular Medicine and Surgery, and Atherosclerosis Research Unit at the Center for Molecular Medicine, ${ }^{c}$ Department of Medicine, Karolinska Institutet, Karolinska University Hospital, Stockholm, Sweden.

Supported by the Tornspiran Foundation, the Mats Kleberg Foundation, the Leducq Foundation, and a donation from Fredrik Lundberg.

Disclosures: Authors have nothing to disclose with regard to commercial support.

Read at The American Association for Thoracic Surgery Aortic Symposium 2014,

New York, New York, April 24-25, 2014.

Received for publication April 17, 2014; revisions received Aug 8, 2014; accepted for publication Aug 13, 2014; available ahead of print Sept 19, 2014.

Address for reprints: Veronica Jackson, MD, PhD, Cardiothoracic Surgery Unit, N3:03, Karolinska University Hospital, 17176 Stockholm, Sweden (E-mail: Veronica.Jackson@karolinska.se).

$0022-5223 / \$ 36.00$

Copyright (C) 2014 by The American Association for Thoracic Surgery

http://dx.doi.org/10.1016/j.jtcvs.2014.08.023
}

aortic valves (TAV), when the surgical correction of aortic valve pathology is indicated. ${ }^{5,6}$ In addition, the BAV population is reported to have a calculated age-adjusted relative risk of aneurysm formation of 86.2 and aortic dissection of 8.4 compared with the general population. ${ }^{7}$ The disproportion of aortic aneurysms and aortic dissection rates may indicate that factors other than aorta size contribute to the incidence of aortic dissection in patients with BAV. ${ }^{7}$

The underlying pathologic mechanisms of aneurysm formation in patients with $\mathrm{TAV}$ and BAV are still not known. There are reports of a genetic predisposition for a weakened aortic wall in patients with $\mathrm{BAV}^{8-11}$ but also of hemodynamic influences on the aortic wall caused by the malformed valve possibly leading to aortic dilatation. ${ }^{12,13}$ Moreover, aneurysm formation in patients with TAV, but not $\mathrm{BAV}$, is associated with an immune response and inflammation of the intima/media region of the aortic wall. ${ }^{14}$ It is well known that atherosclerosis and inflammation play important roles in the pathogenesis of coronary artery disease ${ }^{15}$ as well as in the formation of aortic valve stenosis. ${ }^{16}$

Differences in clinical presentation between patients with $\mathrm{BAV}$ or TAV and aortic valve disease are evident. ${ }^{2,17}$ Whether these differences can be attributed to differences in cardiovascular risks remains uncertain. We evaluated 


\section{Abbreviations and Acronyms \\ ASAP $=$ Advanced Study of Aortic Pathology \\ BAV = bicuspid aortic valve \\ $\mathrm{TAV}=$ tricuspid aortic valve}

patient characteristics, echocardiographic findings, medical history, medication, and laboratory findings in patients undergoing aortic valve surgery with or without concurrent replacement of the ascending aorta and/or concurrent coronary artery bypass grafting.

\section{METHODS}

The study population consisted of a total of 702 patients undergoing cardiac surgery between February 2007 and February 2012.

A total of 500 consecutive patients who underwent surgery because of aortic valve and/or ascending aortic pathology within the setting of the Advanced Study of Aortic Pathology (ASAP), a prospective single center study, ${ }^{5}$ were included. Patients with coronary artery disease, defined as significant stenosis on coronary angiogram, were not included in the ASAP study. Patients were stratified according to valve morphology (TAV/BAV) and ascending aortic morphology (nondilatated or dilatated ascending aorta) based on intraoperative transesophageal echocardiography examination and valve inspection by the surgeon. The definitions of valve pathology and ascending aortic pathology, as well as how the echocardiographic measurements were obtained, have been described in detail previously. ${ }^{5}$ In addition, 202 patients, who were not included in the ASAP study but who had undergone aortic valve surgery during the same time period as patients of the ASAP study, with or without concurrent replacement of the aortic root and/or ascending aorta, who had undergone coronary artery bypass grafting, were included; all medical records were reviewed retrospectively. Patients were stratified according to valve morphology (based on the surgeon's inspection of the valve) and ascending aortic morphology (based on whether the aortic root and/or the ascending aorta was surgically replaced). Measurements of the aortic root and ascending aorta were obtained from preoperative computed tomography examinations. If not available, measurements from the preoperative aortogram or from the preoperative transthoracic echocardiography examination were used. Information on current and previous cardiovascular disease in patients and close relatives, as well as ongoing medication and laboratory findings at the time of surgery were prospectively registered $(n=500)$ and retrospectively reviewed $(n=202)$. For a complete list of variables and parameters analyzed refer to Table E1.

The study was approved by the regional human research ethics committee and informed consent was obtained from all patients.

Patients with unicuspid aortic valves $(n=15)$, and those who underwent isolated ascending aortic replacement $(n=40)$, were not included in the between-group comparisons. Fifteen patients did not undergo preoperative transthoracic echocardiography within the setting of the study due to logistic reasons. In addition, 17 patients who did not meet the criteria of aortic valve stenosis or regurgitation according to the definitions of the study protocol were excluded from the analyses regarding valve pathology.

\section{Statistical Analyses}

Categorical data were summarized using frequency counts and percentages. Continuous data were presented as means \pm standard deviation or as median and interquartile range (P25-P75). The MannWhitney $U$ test and the $t$ test for independent samples were used to compare different subgroups for continuous variables; the $\chi^{2}$ test and Fisher exact test were used for categorical variables. To analyze the effect of isolated valve pathology/combined valve and aortic pathology when controlling for valve stenosis/valve regurgitation, 2-way factorial analysis of variance was used for continuous variables and logistic regression analysis was used for dichotomous variables. In the case of a significant interaction, simple main effects tests were examined; that is, effects of 1 factor holding the other factor fixed. The distribution of some variables was positively skewed; therefore, before the formal parametric analyses, the variables were log-transformed. Analysis of covariance and logistic regression analysis were used to adjust for age. Software used were Statistica (version 10.0, StatSoft, Inc. Tulsa Okla) and SAS (system 9.1, SAS Institute Inc, Cary, NC).

\section{RESULTS}

Of 500 patients without coronary artery disease, $42 \%$ had a TAV and $55 \%$ had a BAV (3\% had a unicuspid aortic valve); $60 \%$ had isolated aortic valve pathology and $32 \%$ had concomitant ascending aortic dilatation $(8 \%$ had isolated aortic dilatation); and $80 \%$ of patients with dilatated aortas had a BAV. The distribution of aortic valve pathology (stenosis/regurgitation) did not differ between TAV and BAV patients with nondilatated aortas $(P=.89)$. With concomitant ascending aortic pathology, valve regurgitation was the most frequent valve pathology in patients with $\mathrm{TAV}$, whereas valve stenosis was more common in patients with BAV $(P<.001)$ (Table 1$)$.

Out of 202 patients with coronary artery disease, $84 \%$ had TAV and 16\% had BAV; $94 \%$ had isolated aortic valve pathology and $6 \%$ had concomitant ascending aortic dilatation. The distribution of valve pathology, predominantly valve stenosis, did not differ between TAV and BAV patients with coronary artery disease and nondilatated aortas $(P=.13)$ (Table 1$)$. When the aorta was dilatated coronary artery disease was uncommon in both patients with TAV and BAV (TAV, 7 out of 38; BAV, 6 out of 127).

A TAV, isolated valve pathology, and coronary artery disease were all associated with more advanced age (approximately 7 years). When the aorta was dilatated, no age differences were observed between the groups, regardless of valve morphology or presence of coronary artery disease (Tables 2-4).

Isolated valve pathology in combination with coronary artery disease was associated with male gender, as was ascending aortic dilatation in patients with TAV without coronary artery disease. There was no difference in gender distribution between patients with TAV and BAV, regardless of valve pathology, presence of aortic pathology, or presence of coronary artery disease (Tables 2-4).

Patient characteristics are given in Table 1 and the distribution of valve morphology in relation to valve pathology, aortic pathology, and coronary artery disease are shown in Figure 1.

\section{Echocardiographic Findings}

In both patients with TAV and BAV, aortic valve peak gradient, mean gradient, and valve area differed between 
TABLE 1. Patient characteristics and echocardiographic findings

\begin{tabular}{|c|c|c|c|c|c|c|c|c|}
\hline \multirow[b]{3}{*}{ Characteristic } & \multicolumn{4}{|c|}{ No CAD $(n=445)$} & \multicolumn{4}{|c|}{$\operatorname{CAD}(n=202)$} \\
\hline & \multicolumn{2}{|c|}{$\operatorname{AV}(n=293)$} & \multicolumn{2}{|c|}{$\mathbf{A V}+\mathbf{A A}(\mathbf{n}=\mathbf{1 5 2})$} & \multicolumn{2}{|c|}{$\mathbf{A V}(\mathbf{n}=\mathbf{1 8 9})$} & \multicolumn{2}{|c|}{$\mathbf{A V}+\mathbf{A A}(\mathbf{n}=\mathbf{1 3})$} \\
\hline & $\begin{array}{c}\text { TAV } \\
(\mathbf{n}=\mathbf{1 5 5})\end{array}$ & $\begin{array}{c}\text { BAV } \\
(\mathbf{n}=\mathbf{1 3 8})\end{array}$ & $\begin{array}{c}\text { TAV } \\
(\mathbf{n}=\mathbf{3 1})\end{array}$ & $\begin{array}{c}\text { BAV } \\
(n=121)\end{array}$ & $\begin{array}{c}\text { TAV } \\
(n=162)\end{array}$ & $\begin{array}{c}\text { BAV } \\
(\mathbf{n}=\mathbf{2 7})\end{array}$ & $\begin{array}{c}\text { TAV } \\
(n=7)\end{array}$ & $\begin{array}{c}\text { BAV } \\
(n=6)\end{array}$ \\
\hline Age (y) & $71 \pm 9$ & $60 \pm 13$ & $64 \pm 12$ & $61 \pm 11$ & $74 \pm 8$ & $67 \pm 7$ & $67 \pm 5$ & $64 \pm 6$ \\
\hline Male/female gender & $92 / 63$ & $93 / 45$ & $25 / 6$ & $93 / 28$ & $124 / 38$ & $24 / 3$ & $7 / 0$ & $5 / 1$ \\
\hline $\operatorname{BSA}\left(\mathrm{m}^{2}\right)$ & $1.94 \pm 0.2$ & $1.94 \pm 0.2$ & $2.03 \pm 0.2$ & $2.00 \pm 0.2$ & $1.98 \pm 0.2$ & $2.02 \pm 0.2$ & $2.06 \pm 0.2$ & $1.95 \pm 0.3$ \\
\hline $\mathrm{SAP}(\mathrm{mm} \mathrm{Hg})$ & $146 \pm 22$ & $142 \pm 20$ & $145 \pm 19$ & $139 \pm 19$ & $143 \pm 21$ & $142 \pm 14$ & $151 \pm 23$ & $142 \pm 20$ \\
\hline DAP $(\mathrm{mm} \mathrm{Hg})$ & $78 \pm 16$ & $80 \pm 12$ & $73 \pm 1$ & $83 \pm 12$ & $76 \pm 10$ & $80 \pm 11$ & $77 \pm 12$ & $76 \pm 11$ \\
\hline AVPG $(\mathrm{mm} \mathrm{Hg})$ & $68(43)$ & $74(35)$ & $12(4)$ & $61(57)$ & $75(27)$ & $74(30)$ & $76(11)$ & $64(29)$ \\
\hline AVMG (mm Hg) & $46(30)$ & $46(21)$ & $6(2)$ & $39(38)$ & $46(18)$ & $46(12)$ & $40(9)$ & $41(14)$ \\
\hline AVA $\left(\mathrm{cm}^{2}\right)$ & $0.8(0.6)$ & $0.8(0.5)$ & $3.1(1.6)$ & $1.0(1.1)$ & $0.8(0.3)$ & $0.8(0.4)$ & - & - \\
\hline LVEDD (mm) & $48(10)$ & $49(11)$ & $59(8)$ & $52(10)$ & $50(12)$ & $49(8)$ & $57(4)$ & $54(32)$ \\
\hline LVESD (mm) & $32(9.5)$ & $34(11)$ & $41(8)$ & $35(10)$ & $46(13)$ & $33(23)$ & $43(5)$ & $31(61)$ \\
\hline $\mathrm{EF}(\%)$ & $60(10)$ & $60(10)$ & $56(8)$ & $60(8)$ & $51(6)$ & $51(10)$ & $61(20)$ & $51(4)$ \\
\hline Aorta $(\mathrm{mm})$ & $33 \pm 5$ & $34 \pm 4$ & $51 \pm 8$ & $46 \pm 6$ & $35 \pm 6$ & $39 \pm 5$ & $54 \pm 10$ & $53 \pm 5$ \\
\hline AS & $110(71)$ & $101(73)$ & $2(6)$ & $74(61)$ & $135(83)$ & 27 (100) & $2(29)$ & $3(50)$ \\
\hline AR & $35(23)$ & $30(22)$ & $27(87)$ & $40(33)$ & $21(13)$ & 0 & $5(71)$ & $3(50)$ \\
\hline
\end{tabular}

Values are given as mean \pm standard deviation, median (interquartile range) (echocardiographic parameters), or frequency (\%). $C A D$, Coronary artery disease; $A V$, isolated aortic valve pathology; $A A$, dilatated ascending aorta; $T A V$, tricuspid aortic valve; $B A V$, bicuspid aortic valve; $B S A$, body surface area; $S A P$, systolic arterial pressure; $D A P$, diastolic arterial pressure; $A V P G$, aortic valve peak gradient; $A V M G$, aortic valve mean gradient; $A V A$, aortic valve area; $L V E D D$, left ventricular end-diastolic diameter; $L V E S D$, left ventricular end-systolic diameter; $E F$, ejection fraction; $A S$, aortic valve stenosis; $A R$, aortic valve regurgitation.

patients with isolated valve pathology and patients with concomitant aortic pathology. It also differed between patients with TAV and BAV with dilatated aortas. These differences were related to the distribution of valve pathology in the groups (Tables 1-4), as were the differences in left ventricular diameter in the TAV group with no coronary artery disease (Table 2), and between patients with TAV and BAV with dilatated aortas (Table 4). In patients with TAV with combined valve pathology and coronary artery disease, aortic valve peak gradient was higher and aortic valve area smaller compared with patients with TAV with isolated valve disease. This was related to age. Thus, patients with TAV with coronary artery disease were older and therefore had more severe aortic stenosis than patients with TAV without coronary artery disease (Table 2).

A lower ejection fraction and a larger ascending aortic diameter were both associated with coronary artery disease in patients with TAV and patients with BAV with isolated valve pathology, as well as in patients with BAV with concomitant aortic dilatation (Tables 1-3). For patients with coronary artery disease, patients with BAV with isolated valve pathology had larger ascending aortas than the corresponding group of patients with TAV. For patients without coronary artery disease, patients with TAV with dilatated aortas had larger ascending aortas than the corresponding group of patients with BAV (Table 4).

\section{Medical History}

In general, and apparent in both patients with TAV and $\mathrm{BAV}$, isolated valve pathology and coronary artery disease were associated with a higher prevalence of comorbid conditions and of relatives with cardiovascular disease. This was also true for patients with TAV with isolated valve pathology and no coronary artery disease. Arterial hypertension and a history of stroke were more common in the TAV group than in the BAV group (Tables 2-4). For a complete list of parameters analyzed refer to Table E1.

\section{Medical Treatment}

A TAV, isolated valve pathology, and coronary artery disease were associated with ongoing pharmacologic treatment of cardiovascular disease (Tables 2-4). For a complete list of analyzed parameters refer to Table E1.

\section{Laboratory Findings}

Coronary artery disease, and thereby advanced age, was associated with higher levels of creatinine and C-reactive protein in patients with BAV with isolated valve pathology (Table 3). Patients with TAV without coronary artery disease had higher levels of creatinine and C-reactive protein than patients with BAV, regardless of valve and aortic pathology (Table 4). For a complete list of variables analyzed refer to Table E1.

\section{DISCUSSION}

Our study demonstrates that a BAV was more common than a TAV in patients without coronary artery disease $(P<.001)$, whereas a TAV was markedly more common in patients with coronary artery disease $(P<.001) ; 80 \%$ of patients with combined valve and aortic pathology but no coronary artery disease had a BAV; patients with aortic 
TABLE 2. Clinical parameters and variables in relation to valve, aortic, and coronary artery pathology in patients with tricuspid aortic valves (TAVs)

\begin{tabular}{|c|c|c|c|}
\hline Parameter/variable & $\mathbf{A V}(\mathbf{n}=\mathbf{1 5 5})$ & $\mathbf{A V}+\mathbf{A} \mathbf{A}(\mathbf{n}=\mathbf{3 1})$ & $P$ value \\
\hline \multicolumn{4}{|l|}{ TAV patients without CAD } \\
\hline Age (y) & $71 \pm 9$ & $64 \pm 12$ & .001 \\
\hline Male/female gender & $92 / 63$ & $25 / 6$ & .02 \\
\hline Body surface area $\left(\mathrm{m}^{2}\right)$ & $1.94 \pm 0.2$ & $2.03 \pm 0.2$ & .02 \\
\hline Diastolic blood pressure $(\mathrm{mm} \mathrm{Hg})$ & $78 \pm 16$ & $73 \pm 1$ & .02 \\
\hline Aortic valve peak gradient (mm Hg) & $68(43)$ & $12(4)$ & $<.001$ \\
\hline Aortic valve mean gradient (mm $\mathrm{Hg})$ & $46(30)$ & $6(2)$ & $<.001$ \\
\hline Aortic valve area $\left(\mathrm{cm}^{2}\right)$ & $0.8(0.5)$ & $3.1(1.6)$ & $<.001$ \\
\hline LV end-diastolic diameter (mm) & $48(10)$ & $59(8)$ & $<.001$ \\
\hline LV end-systolic diameter (mm) & $32(9.5)$ & $41(8)$ & $<.001$ \\
\hline Diabetes* & $22(14)$ & 0 & .01 \\
\hline Relative $\dagger$ with VOC & $24(16)$ & $1(3)$ & .04 \\
\hline \multirow[t]{2}{*}{ Calcium inhibitor } & $36(23)$ & $2(7)$ & .03 \\
\hline & $\mathrm{AV}(\mathrm{n}=162)$ & $\mathbf{A V}+\mathbf{A} \mathbf{A}(\mathbf{n}=7)$ & \\
\hline \multicolumn{4}{|l|}{ TAV patients with CAD } \\
\hline Age (y) & $74 \pm 8$ & $67 \pm 5$ & .01 \\
\hline Relative $\dagger$ with stroke & $19(13)$ & $4(57)$ & .01 \\
\hline \multirow[t]{2}{*}{ ACE inhibitor } & $46(28)$ & $5(71)$ & .03 \\
\hline & No CAD $(n=155)$ & $\operatorname{CAD}(n=162)$ & \\
\hline \multicolumn{4}{|l|}{ TAV patients with isolated valve pathology } \\
\hline Age (y) & $71 \pm 9$ & $74 \pm 8$ & .03 \\
\hline Male/female gender & $92 / 63$ & $124 / 38$ & $<.001$ \\
\hline Aortic valve peak gradient $(\mathrm{mm} \mathrm{Hg})$ & $68(43)$ & $75(27)$ & .04 \\
\hline Aortic valve area $\left(\mathrm{cm}^{2}\right)$ & $0.8(0.6)$ & $0.8(0.3)$ & .01 \\
\hline LV end-systolic diameter (mm) & $32(9.5)$ & $46(13)$ & .004 \\
\hline Ejection fraction $(\%)$ & $60(10)$ & $51(6)$ & $<.001$ \\
\hline Ascending aortic diameter (mm) & $33 \pm 5$ & $35 \pm 6$ & .01 \\
\hline Hypertension* & $100(65)$ & $143(88)$ & $<.001$ \\
\hline Relative with sudden death & $12(8)$ & $39(26)$ & $<.001$ \\
\hline Beta blocker & $74(48)$ & $108(67)$ & $<.001$ \\
\hline Acetylsalicylic acid & $69(45)$ & $110(68)$ & $<.001$ \\
\hline Lipid-lowering agent & $79(51)$ & $127(78)$ & $<.001$ \\
\hline Insulin & $3(2)$ & $14(9)$ & $<.001$ \\
\hline \multirow[t]{2}{*}{ Long-acting nitrate } & $7(5)$ & $34(21)$ & $<.001$ \\
\hline & No CAD $(n=31)$ & $\operatorname{CAD}(\mathbf{n}=7)$ & \\
\hline \multicolumn{4}{|c|}{ TAV patients with concomitant valve and aortic pathology } \\
\hline Aortic valve peak gradient (mm Hg) & $12(4)$ & $76(11)$ & .02 \\
\hline Aortic valve mean gradient ( $\mathrm{mm} \mathrm{Hg}$ ) & $6(2)$ & $40(9)$ & .02 \\
\hline Relative $\dagger$ with sudden death & $2(7)$ & $3(43)$ & .04 \\
\hline Relative $\dagger$ with stroke & $4(13)$ & $4(57)$ & .02 \\
\hline
\end{tabular}

Values are given as mean \pm standard deviation, median (interquartile range) (echocardiographic parameters), or frequency (\%). For a complete list of variables and parameters analyzed refer to Table $\mathrm{E} 1 . A V$, Isolated aortic valve pathology; $A A$, dilatated ascending aorta; $C A D$, coronary artery disease; $L V$, left ventricular; $V O C$, valvular heart disease; $A C E$, angiotensin converting enzyme; $T A V$, tricuspid aortic valve. *As defined by ongoing medical treatment. †Parent or sibling with diagnosis before age 65 years.

valve pathology and concomitant coronary artery disease were rarely subjected to ascending aortic replacement (with coronary artery disease $6 \%$, without $32 \%$; $P<.001)$; all patients with BAV and $83 \%$ of patients with TAV with coronary artery disease who underwent isolated aortic valve surgery had aortic valve stenosis; coronary artery disease was associated with TAV, advanced age, and male gender; and patients with TAV were older than patients with BAV regardless of concomitant coronary artery disease.

The finding that patients with BAV rarely had coronary artery disease whereas the condition was associated with TAV, advanced age, and male gender is in agreement with previous work. ${ }^{2,18}$ However, the difference in the frequency of coronary artery disease between TAV and BAV patients was greater in our study (TAV $86 \%$ vs BAV 
TABLE 3. Clinical parameters and variables in relation to valve, aortic, and coronary artery pathology in patients with bicuspid aortic valves (BAVs)

\begin{tabular}{|c|c|c|c|}
\hline & $\mathrm{AV}(\mathbf{n}=\mathbf{1 3 8})$ & $\mathbf{A V}+\mathbf{A A}(\mathbf{n}=\mathbf{1 2 1})$ & $P$ value \\
\hline \multicolumn{4}{|l|}{$\mathrm{BAV}$ patients without $\mathrm{CAD}$} \\
\hline Body surface area $\left(\mathrm{m}^{2}\right)$ & $1.94 \pm 0.2$ & $2.00 \pm 0.2$ & .03 \\
\hline Aortic valve peak gradient (mm Hg) & $74(35)$ & $61(57)$ & .005 \\
\hline Aortic valve mean gradient $(\mathrm{mm} \mathrm{Hg})$ & $46(21)$ & $39(38)$ & .01 \\
\hline \multirow[t]{2}{*}{ Aortic valve area $\left(\mathrm{cm}^{2}\right)$} & $0.8(0.5)$ & $1.0(1.1)$ & .003 \\
\hline & $\mathbf{A V}(\mathbf{n}=\mathbf{2 7})$ & $\mathbf{A V}+\mathbf{A A}(\mathbf{n}=\mathbf{6})$ & \\
\hline \multicolumn{4}{|l|}{ BAV patients with CAD } \\
\hline \multirow[t]{2}{*}{ Lipid-lowering agent } & $21(81)$ & $1(20)$ & .02 \\
\hline & No CAD $(n=138)$ & CAD $(\mathbf{n}=27)$ & \\
\hline \multicolumn{4}{|l|}{ BAV patients with isolated valve pathology } \\
\hline Age (y) & $60 \pm 13$ & $67 \pm 7$ & .002 \\
\hline Male/female gender & $93 / 45$ & $24 / 3$ & .02 \\
\hline Ejection fraction $(\%)$ & $60(10)$ & $51(10)$ & .003 \\
\hline Ascending aortic diameter (mm) & $34 \pm 4$ & $39 \pm 5$ & $<.001$ \\
\hline Hypertension* & $66(48)$ & $23(85)$ & $<.001$ \\
\hline Relative with sudden death & $18(14)$ & $7(32)$ & .04 \\
\hline Beta blocker & $56(41)$ & $19(73)$ & .003 \\
\hline Acetylsalicylic acid & $42(31)$ & $21(81)$ & $<.001$ \\
\hline Lipid-lowering agent & $48(35)$ & $21(81)$ & $<.001$ \\
\hline Thiazide diuretics & $12(8)$ & $7(27)$ & .02 \\
\hline Long-acting nitrate & $2(1)$ & $3(12)$ & .03 \\
\hline Creatinine $\dagger(\mu \mathrm{mol} / \mathrm{L})$ & $78(22)$ & $84(22)$ & .03 \\
\hline \multirow[t]{2}{*}{ C-reactive protein $\ddagger(\mathrm{mg} / \mathrm{L})$} & $1(2)$ & $3(3)$ & .007 \\
\hline & No CAD $(\mathbf{n}=121)$ & CAD $(n=6)$ & \\
\hline \multicolumn{4}{|c|}{ BAV patients with concomitant valve and aortic pathology } \\
\hline Ejection fraction $(\%)$ & $60(8)$ & $51(4)$ & .02 \\
\hline Ascending aortic diameter $(\mathrm{mm})$ & $46 \pm 6$ & $53 \pm 5$ & .02 \\
\hline Acetylsalicylic acid & $25(21)$ & $4(80)$ & .01 \\
\hline Other antiplatelet agent & 0 & $1(20)$ & .04 \\
\hline
\end{tabular}

$16 \%$ ) than previously reported. ${ }^{2,18}$ Patients with coronary artery disease, apparent in both patients with TAV and BAV, had a higher prevalence of factors associated with cardiovascular risk, manifest cardiovascular disease, and comorbid conditions at the time of surgery (TAV: advanced age, male gender, more severe valve stenosis, larger ventricular dimensions, and lower ejection fraction and TAV and BAV: larger ascending aorta, arterial hypertension, relatives who died suddenly, and ongoing pharmacologic treatment of cardiovascular disease).

Previous reports on age, coronary artery disease, and concomitant coronary artery bypass grafting show these as predictors of mortality in patients undergoing aortic valve surgery, although the distinction between TAV and BAV is not made. ${ }^{19}$ In our study, combined valve and coronary artery pathology was predominantly found in patients with TAV. Thus, valve morphology (TAV or BAV) may be associated with differences in outcome in patients undergoing isolated valve surgery versus valve surgery with concurrent coronary artery bypass grafting. Roberts and colleagues ${ }^{18}$ reported no difference in long-term survival in patients undergoing aortic valve replacement with or without concurrent coronary artery bypass grafting, but found a greater probability of survival in patients with uni- or bicuspid aortic valves than in patients with TAV. Subsequently, it was concluded that valve morphology, but not concomitant coronary artery bypass grafting, affected the probability of survival. ${ }^{18}$ Beach and colleagues $^{20}$ also reported on the lack of effects of coronary artery disease on survival in patients undergoing aortic valve replacement with or without intervention for concomitant coronary artery disease. In our study medical history, medication, and laboratory findings did not widely differ between patients with TAV and BAV with coronary artery disease. The distribution of valve pathology was also similar in the groups where valve stenosis was predominant, regardless of valve morphology or presence of coronary artery disease. By contrast, patients with TAV 
TABLE 4. Comparison of clinical parameters and variables in relation to valve, aortic, and coronary artery pathology, between patients with tricuspid aortic valves (TAVs) and bicuspid aortic valves (BAVs)

\begin{tabular}{|c|c|c|c|}
\hline & TAV $(\mathbf{n}=\mathbf{1 5 5})$ & BAV $(\mathbf{n}=138)$ & $P$ value \\
\hline \multicolumn{4}{|c|}{ Patients with isolated valve pathology without CAD } \\
\hline Age (y) & $71 \pm 9$ & $60 \pm 13$ & $<.001$ \\
\hline Acetylsalicylic acid & $69(45)$ & $42(31)$ & .02 \\
\hline Lipid-lowering agent & $79(51)$ & $48(35)$ & .009 \\
\hline Calcium inhibitor & $36(23)$ & $17(13)$ & .02 \\
\hline Thiazide diuretics & $36(23)$ & $12(8)$ & .001 \\
\hline Creatinine $\dagger(\mu \mathrm{mol} / \mathrm{L})$ & $82(22)$ & $78(22)$ & .02 \\
\hline C-reactive protein $\ddagger$ (mg/L) & $2(3)$ & $1(2)$ & .01 \\
\hline Hypertension* & $100(65)$ & $66(48)$ & .005 \\
\hline \multirow[t]{2}{*}{ Previous stroke } & $24(15)$ & $9(7)$ & .02 \\
\hline & TAV $(n=162)$ & BAV $(\mathbf{n}=\mathbf{2 7})$ & \\
\hline \multicolumn{4}{|c|}{ Patients with isolated valve pathology and CAD } \\
\hline Age (y) & $74 \pm 8$ & $67 \pm 7$ & $<.001$ \\
\hline Anticoagulant & $32(20)$ & 0 & .009 \\
\hline \multirow[t]{2}{*}{ Ascending aortic diameter $(\mathrm{mm})$} & $35 \pm 6$ & $39 \pm 5$ & .007 \\
\hline & TAV $(\mathbf{n}=\mathbf{3 1})$ & $\operatorname{BAV}(\mathbf{n}=121)$ & \\
\hline \multicolumn{4}{|c|}{ Patients with concomitant valve and aortic pathology without CAD } \\
\hline Diastolic blood pressure $(\mathrm{mm} \mathrm{Hg})$ & $73 \pm 1$ & $83 \pm 12$ & $<.001$ \\
\hline Other platelet agent & $2(1)$ & 0 & .04 \\
\hline Creatinine $\dagger(\mu \mathrm{mol} / \mathrm{L})$ & $90(21)$ & $80(16)$ & .04 \\
\hline C-reactive protein $\ddagger$ (mg/L) & $2(3)$ & $1(2)$ & .008 \\
\hline Aortic valve peak gradient (mm Hg) & $12(4)$ & $61(57)$ & $<.001$ \\
\hline Aortic valve mean gradient $(\mathrm{mm} \mathrm{Hg})$ & $6(2)$ & $39(38)$ & $<.001$ \\
\hline Aortic valve area $\left(\mathrm{cm}^{2}\right)$ & $3.1(1.6)$ & $1.0(1.1)$ & $<.001$ \\
\hline LV end-diastolic diameter (mm) & $59(8)$ & $52(10)$ & $<.001$ \\
\hline LV end-systolic diameter (mm) & $41(8)$ & $35(10)$ & $<.001$ \\
\hline Ascending aortic diameter $(\mathrm{mm})$ & $51 \pm 8$ & $46 \pm 6$ & $<.001$ \\
\hline
\end{tabular}

Values are given as mean \pm standard deviation, median (interquartile range) (echocardiographic parameters), or frequency (\%). $C A D$, Coronary artery disease; $L V$, left ventricular; $T A V$, tricuspid aortic valve; $B A V$, bicuspid aortic valve. *As defined by ongoing medical treatment. $\dagger$ Reference value: creatinine $<90 \mu$ mol/L. $\ddagger$ Reference value: C-reactive protein $<3 \mathrm{mg} / \mathrm{L}$.

with isolated valve pathology and no coronary artery disease were older, experienced a higher incidence of arterial hypertension, a history of stroke, ongoing medical treatment for cardiovascular disease, and higher creatinine levels than the corresponding group of patients with BAV. These findings suggest that valve morphology may constitute a higher risk of mortality in patients undergoing cardiac surgery, which is likely due to the more pronounced

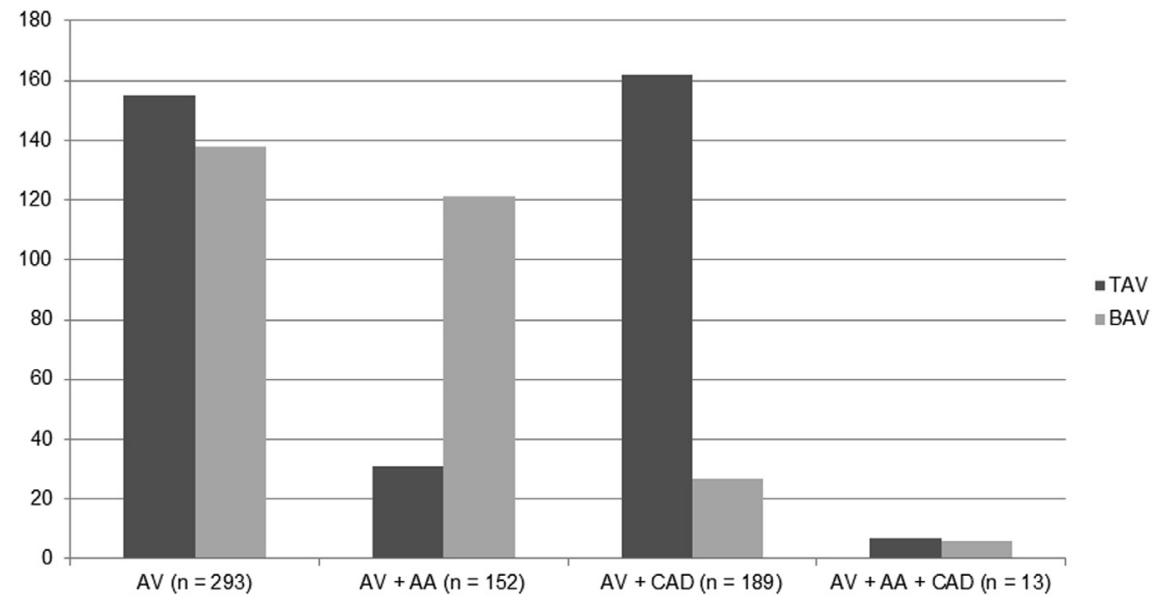

FIGURE 1. Distribution of valve morphology in relation to valve pathology, aortic morphology, and coronary artery disease. $B A V$, Bicuspid aortic valve; $T A V$, tricuspid aortic valve; $A V$, isolated aortic valve pathology; $A A$, dilatated ascending aorta; $C A D$, coronary artery disease. 
cardiovascular risks that patients with TAV seem to carry even without manifest coronary artery disease. ${ }^{20}$ In agreement with these findings, in our study the relative distribution of BAV decreased substantially in the presence of coronary artery disease.

The pathogenesis of aneurysm formation of the ascending, descending, and abdominal aorta differs. ${ }^{21,22}$ Aneurysm formation is associated with degeneration of the media of the aortic wall. ${ }^{8,21}$ On a progressive scale (ascending $<$ descending $<$ abdominal) it is associated with atherosclerosis and inflammation. ${ }^{23,24}$ Moreover, aneurysm formation of the ascending aorta in patients with TAV (but not BAV) is associated with inflammation and immune responses. ${ }^{10,14}$ Atherosclerosis and inflammation are important factors in the development of valve stenosis and coronary artery disease ${ }^{15,16}$ and coronary artery disease is a common finding in patients undergoing endovascular or surgical repair of descending, thoracoabdominal, or abdominal aortic aneurysms. ${ }^{25,26}$

Patients with TAV with dilatated aortas very rarely had aortic valve stenosis. In addition, the combination of valve pathology, coronary artery disease, and ascending aortic dilatation was markedly rare. Thus, valve stenosis, with or without coronary artery disease, was common in patients with TAV when the aorta was not dilatated, but uncommon when the aorta was dilatated. Despite the association of inflammation and aneurysm formation in patients with $\mathrm{TAV}$, the combination of valve stenosis, coronary artery disease, and aortic dilatation was rare in patients with $\mathrm{TAV}$, as well as in patients with BAV. BAV is frequently associated with ascending aortic dilatation, which in turn is rarely associated with coronary artery disease. Thus, valve morphology may have an influence on the development of coronary artery disease.

These findings may serve as grounds for choosing a less invasive method of preoperative examination of the coronary arteries (ie, computed tomography angiogram instead of coronary angiogram) in patients with BAV without a history of angina, as well as in patients scheduled for ascending aortic surgery regardless of valve morphology.

\section{Study Limitations}

The study population consisted of surgical patients only; therefore, the results may not be applicable to individuals with TAV or BAV without indications for surgical intervention. The mix of prospective and retrospective data is not optimal and the retrospective cohort $(n=202)$ contains more missing values than the prospective cohort $(\mathrm{n}=500)$. However, in the prospective cohort missing values were rare and the study was a single center study with a limited number of surgeons involved. This enabled uniformity in the diagnosis, surgical procedures, and data collecting. Moreover, statistical analyses were performed by an external statistician and the results were considered valid.

\section{CONCLUSIONS}

Coronary artery disease is uncommon in BAV disease but is associated with TAV disease, advanced age, and male gender. Ascending aortic dilatation is predominantly found in BAV disease. Coronary artery disease and ascending aortic dilatation rarely coexist regardless of TAV or BAV. Differences in the prevalence of coronary artery disease or ascending aortic dilatation between TAV and BAV patients are not explained by differences in risk factors for cardiovascular disease or distribution of valve pathology. Possible beneficial effects of BAV morphology in cardiovascular disease need to be further evaluated.

The authors thank Elisabeth Berg, Medical Statistics Unit, Department of Learning, Informatics, Management, and Ethics, Karolinska Institutet, for her assistance in performing the statistical analyses.

\section{References}

1. Cripe L, Andelfinger G, Martin LJ, Shooner K, Benson DW. Bicuspid aortic valve is heritable. J Am Coll Cardiol. 2004;44:138-43.

2. Bauer M, Bauer U, Siniawski H, Hetzer R. Differences in clinical manifestations in patients with bicuspid and tricuspid aortic valves undergoing surgery of the aortic valve and/or ascending aorta. Thorac Cardiovasc Surg. 2007;55:485-90.

3. Huntington K, Hunter AG, Chan KL. A prospective study to assess the frequency of familial clustering of congenital bicuspid aortic valve. J Am Coll Cardiol. 1997;30:1809-12.

4. Roberts WC, Vowels TJ, Ko JM. Natural history of adults with congenitally malformed aortic valves (unicuspid or bicuspid). Medicine (Baltimore). 2012 91:287-308.

5. Jackson V, Petrini J, Caidahl K, Eriksson MJ, Liska J, Eriksson P, et al. Bicuspid aortic valve leaflet morphology in relation to aortic root morphology: a study of 300 patients undergoing open-heart surgery. Eur J Cardiothorac Surg. 2011;40: e118-24.

6. Collins MJ, Butany J, Borger MA, Strauss BH, David TE. Implications of a congenitally abnormal valve: a study of 1025 consecutively excised aortic valves. J Clin Pathol. 2008;61:530-6.

7. Michelena HI, Khanna AD, Mahoney D, Margaryan E, Topilsky Y, Suri RM, et al. Incidence of aortic complications in patients with bicuspid aortic valves. JAMA. 2011;306:1104-12.

8. Fedak PW, de Sa MP, Verma S, Nili N, Kazemian P, Butany J, et al. Vascular matrix remodeling in patients with bicuspid aortic valve malformations: implications for aortic dilatation. J Thorac Cardiovasc Surg. 2003;126:797-806.

9. Pepe G, Nistri S, Giusti B, Sticchi E, Attanasio M, Porciani C, et al. Identification of fibrillin 1 gene mutations in patients with bicuspid aortic valve (BAV) without Marfan syndrome. BMC Med Genet. 2014;15:23.

10. Grewal N, Gittenberger-de Groot AC, Poelmann RE, Klautz RJ, Lindeman JH Goumans MJ, et al. Ascending aorta dilation in association with bicuspid aortic valve: a maturation defect of the aortic wall. J Thorac Cardiovasc Surg. January 25, 2014 [Epub ahead of print].

11. McKellar SH, Tester DJ, Yagubyan M, Majumdar R, Ackerman MJ, Sundt TM 3rd. Novel notch1 mutations in patients with bicuspid aortic valve disease and thoracic aortic aneurysms. J Thorac Cardiovasc Surg. 2007;134:290-6.

12. Mahadevia R, Barker AJ, Schnell S, Entezari P, Kansal P, Fedak PW, et al Bicuspid aortic cusp fusion morphology alters aortic three-dimensional outflow patterns, wall shear stress, and expression of aortopathy. Circulation. 2014;129: 673-82.

13. Della Corte A, Bancone C, Conti CA, Votta E, Redaelli A, Del Viscovo L, et al Restricted cusp motion in right-left type of bicuspid aortic valves: a new risk marker for aortopathy. J Thorac Cardiovasc Surg. 2012;144:360-9.

14. Folkersen L, Wagsater D, Paloschi V, Jackson V, Petrini J, Kurtovic S, et al Unraveling the divergent gene expression profiles in bicuspid and tricuspid aortic valve patients with thoracic aortic dilatation - the ASAP study. Mol Med. 2011; 17:1365-73.

15. Hansson GK. Inflammation, atherosclerosis, and coronary artery disease. $N$ Eng J Med. 2005;352:1685-95. 
16. Ngo DT, Sverdlov AL, Horowitz JD. Prevention of aortic valve stenosis: a realistic therapeutic target? Pharmacol Ther. 2012;135:78-93.

17. Jackson V, Olsson C, Eriksson P, Franco-Cereceda A. Aortic dimensions in patients with bicuspid and tricuspid aortic valves. J Thorac Cardiovasc Surg. 2013;146:605-10.

18. Roberts WC, Roberts CC, Vowels TJ, Ko JM, Filardo G, Hamman BL, et al. Effect of coronary bypass and valve structure on outcome in isolated valve replacement for aortic stenosis. Am J Cardiol. 2012;109:1334-40.

19. Tjang YS, van Hees Y, Korfer R, Grobbee DE, van der Heijden GJ. Predictors of mortality after aortic valve replacement. Eur J Cardiothorac Surg. 2007;32: 469-74.

20. Beach JM, Mihaljevic T, Svensson LG, Rajeswaran J, Marwick T, Griffin B, et al. Coronary artery disease and outcomes of aortic valve replacement for severe aortic stenosis. J Am Coll Cardiol. 2013;61:837-48.

21. Nordon I, Brar R, Taylor J, Hinchliffe R, Loftus IM, Thompson MM. Evidence from cross-sectional imaging indicates abdominal but not thoracic aortic aneurysms are local manifestations of a systemic dilating diathesis. $J$ Vasc Surg. 2009;50:171-6.

22. Jondeau G, Boileau C. Genetics of thoracic aortic aneurysms. Curr Atheroscler Rep. 2012;14:219-26.

23. Montgomery DH, Ververis JJ, McGorisk G, Frohwein S, Martin RP, Taylor WR. Natural history of severe atheromatous disease of the thoracic aorta: a transesophageal echocardiographic study. J Am Coll Cardiol. 1996;27:95-101.

24. Isselbacher EM. Thoracic and abdominal aortic aneurysms. Circulation. 2005; 111:816-28.

25. Kieffer E, Chiche L, Baron JF, Godet G, Koskas F, Bahnini A. Coronary and carotid artery disease in patients with degenerative aneurysm of the descending thoracic or thoracoabdominal aorta: prevalence and impact on operative mortality. Ann Vasc Surg. 2002;16:679-84.

26. Marin ML, Hollier LH, Ellozy SH, Spielvogel D, Mitty H, Griepp R, et al. Endovascular stent graft repair of abdominal and thoracic aortic aneurysms: a 10-year experience with 817 patients. Ann Surg. 2003;238:586-93. 
TABLE E1. Complete list of parameters analyzed

\begin{tabular}{|c|c|c|c|c|c|c|c|c|}
\hline & \multicolumn{4}{|c|}{ No CAD $(n=445)$} & \multicolumn{4}{|c|}{$\operatorname{CAD}(n=202)$} \\
\hline & \multicolumn{2}{|c|}{$\mathrm{AV}(\mathrm{n}=\mathbf{2 9 3})$} & \multicolumn{2}{|c|}{$\mathbf{A V}+\mathbf{A A}(\mathbf{n}=\mathbf{1 5 2})$} & \multicolumn{2}{|c|}{$\mathrm{AV}(\mathbf{n}=\mathbf{1 8 9})$} & \multicolumn{2}{|c|}{$\mathbf{A V}+\mathbf{A A}(\mathbf{n}=\mathbf{1 3})$} \\
\hline & $\begin{array}{c}\text { TAV } \\
(\mathbf{n}=\mathbf{1 5 5})\end{array}$ & $\begin{array}{c}\text { BAV } \\
(\mathbf{n}=\mathbf{1 3 8})\end{array}$ & $\begin{array}{c}\text { TAV } \\
(\mathbf{n}=\mathbf{3 1})\end{array}$ & $\begin{array}{c}\text { BAV } \\
(\mathbf{n}=\mathbf{1 2 1})\end{array}$ & $\begin{array}{c}\text { TAV } \\
(n=162)\end{array}$ & $\begin{array}{c}\text { BAV } \\
(\mathbf{n}=\mathbf{2 7})\end{array}$ & $\begin{array}{c}\text { TAV } \\
(\mathbf{n}=7)\end{array}$ & $\begin{array}{c}\text { BAV } \\
(n=6)\end{array}$ \\
\hline \multicolumn{9}{|l|}{ Medical history } \\
\hline Arterial hypertension* & $100(65)$ & $66(48)$ & $16(52)$ & $55(45)$ & $143(88)$ & $23(85)$ & $6(86)$ & $5(83)$ \\
\hline Diabetes mellitus* & $22(14)$ & $19(14)$ & 0 & $9(7)$ & $31(19)$ & $5(19)$ & 0 & 0 \\
\hline Stroke & $24(15)$ & $9(7)$ & $4(13)$ & $8(7)$ & $22(14)$ & $4(15)$ & 0 & 0 \\
\hline Peripheral arterial disease & $20(13)$ & $16(12)$ & $1(3)$ & $8(7)$ & $15(9)$ & $1(4)$ & $1(14)$ & $1(20)$ \\
\hline Relative $\nmid$ with MI/AP & $55(36)$ & $39(29)$ & $9(29)$ & $42(35)$ & $63(41)$ & $7(32)$ & $4(31)$ & $2(33)$ \\
\hline Relative $\dagger$ with stroke & $24(16)$ & $19(14)$ & $4(13)$ & $14(12)$ & $19(13)$ & $1(5)$ & $4(57)$ & $2(33)$ \\
\hline Relative $\nmid$ with VOC & $24(16)$ & $18(13)$ & $1(3)$ & $13(11)$ & $27(19)$ & $1(5)$ & $2(29)$ & $2(33)$ \\
\hline Relative $\dagger$ who died suddenly & $12(8)$ & $18(14)$ & $2(7)$ & $9(8)$ & $39(26)$ & $7(32)$ & $3(43)$ & $1(17)$ \\
\hline \multicolumn{9}{|l|}{ Medical treatment } \\
\hline Beta blocker & $74(48)$ & $56(41)$ & $12(40)$ & $43(36)$ & $108(67)$ & $19(73)$ & $4(57)$ & $3(60)$ \\
\hline Acetylsalicylic acid & $69(45)$ & $42(31)$ & $9(30)$ & $25(21)$ & $110(68)$ & $21(81)$ & $4(57)$ & $4(80)$ \\
\hline Other antiplatelet agent & $6(4)$ & $3(2)$ & $2(1)$ & 0 & $11(7)$ & $3(12)$ & 0 & $1(20)$ \\
\hline Anticoagulant & $21(14)$ & $10(7)$ & $4(13)$ & $17(14)$ & $32(20)$ & 0 & 0 & 0 \\
\hline Lipid-lowering agent & $79(51)$ & $48(35)$ & $6(20)$ & $36(30)$ & $127(78)$ & $21(81)$ & $4(57)$ & $1(20)$ \\
\hline Calcium inhibitor & $36(23)$ & $17(13)$ & $2(7)$ & $20(17)$ & $38(23)$ & $6(23)$ & $2(29)$ & $2(40)$ \\
\hline Carvedilol & $1(1)$ & $1(1)$ & 0 & $1(1)$ & $2(1)$ & $1(4)$ & 0 & 0 \\
\hline ACE inhibitor & $46(30)$ & $31(23)$ & $9(30)$ & $23(19)$ & $46(28)$ & $5(19)$ & $5(71)$ & $3(60)$ \\
\hline ARB & $29(19)$ & $15(11)$ & $9(30)$ & $16(13)$ & $25(15)$ & $5(19)$ & $2(17)$ & $1(20)$ \\
\hline Loop diuretics & $31(20)$ & $16(12)$ & $5(17)$ & $16(13)$ & $44(27)$ & $4(15)$ & $4(57)$ & $1(20)$ \\
\hline Thiazide diuretics & $36(23)$ & $12(8)$ & $5(17)$ & $14(12)$ & $27(17)$ & $7(27)$ & $2(29)$ & 0 \\
\hline Oral antidiabetes agent & $17(11)$ & $9(7)$ & $1(3)$ & $3(3)$ & $21(13)$ & $4(15)$ & 0 & 0 \\
\hline Insulin & $3(2)$ & $7(15)$ & 0 & $2(2)$ & $14(9)$ & $2(7)$ & 0 & 0 \\
\hline Long-acting nitrate & $7(5)$ & $2(1)$ & $1(3)$ & $1(1)$ & $34(21)$ & $3(12)$ & 0 & 0 \\
\hline \multicolumn{9}{|l|}{ Laboratory finding } \\
\hline Creatinine $\ddagger(\mu \mathrm{mol} / \mathrm{L})$ & $82(22)$ & $78(22)$ & $90(21)$ & $80(16)$ & $87(31)$ & $84(22)$ & $86(52)$ & $82(18)$ \\
\hline C-reactive protein $\S(\mathrm{mg} / \mathrm{L})$ & $2(3)$ & $1(2)$ & $2(3)$ & $1(2)$ & $2(4)$ & $3(3)$ & $13(16)$ & $2(2)$ \\
\hline Triglycerides $\|(\mathrm{mmol} / \mathrm{L})$ & $1.3(1.0)$ & $1.0(0.8)$ & $1.1(0.9)$ & $1.1(0.8)$ & $1.1(0.5)$ & $1.3(1.5)$ & - & - \\
\hline Cholesterol $\Upsilon(\mathrm{mmol} / \mathrm{L})$ & $4.9(1.3)$ & $4.9(1.4)$ & $4.9(1.4)$ & $5.2(1.4)$ & $4.1(0.5)$ & $5.9(3.4)$ & - & - \\
\hline High-density lipoprotein\# (mmol/L) & $1.2(0.6)$ & $1.3(0.7)$ & $1.3(0.3)$ & $1.3(0.5)$ & $1.0(0.7)$ & $1.4(0.6)$ & - & - \\
\hline Low-density lipoprotein $* *(\mathrm{mmol} / \mathrm{L})$ & $2.8(1.3)$ & $3.0(1.4)$ & $3.2(0.9)$ & $3.1(1.3)$ & $2.4(0.8)$ & $4.1(3.3)$ & - & - \\
\hline
\end{tabular}

